\title{
The Context of Color: A Study on the Visual Color of the City-Taking Chengdu as an Example
}

\author{
Mingyi Wu, Yuchen Feng \\ Art College, Sichuan University, Chengdu, China \\ Email: wumingyi96@163.com
}

How to cite this paper: Wu, M. Y., \& Feng, Y. C. (2022). The Context of Color: A Study on the Visual Color of the City-Taking Chengdu as an Example. Art and Design Review, 10, 29-40.

https://doi.org/10.4236/adr.2022.101003

Received: November 21, 2021

Accepted: January 10, 2022

Published: January 13, 2022

Copyright () 2022 by author(s) and Scientific Research Publishing Inc. This work is licensed under the Creative Commons Attribution International License (CC BY 4.0).

http://creativecommons.org/licenses/by/4.0/

\begin{abstract}
With the continuous advancement of urbanization, China's urban color planning has begun to receive attention, but there are still many problems in the use of urban colors. In order to further clarify the color positioning of the city, the color history of the city and the application of contemporary urban color can be investigated, and then the color range with urban characteristics can be summarized through analysis and comparison, so as to scientifically guide the color planning of the future city. Taking Chengdu as an example, this paper examines the origin and context of the use of colors in Chengdu, and at the same time investigates the current status of the use of environmental colors in Chengdu. The two confirm each other and summarize several representative colors in Chengdu. It provides a basis for the application of future urban color, and also provides a certain reference value for future urban color images and other related research.
\end{abstract}

\section{Keywords}

Visual Color, Urban Color, Historical Context, Color Research

\section{Introduction}

The color of the city usually appears as an important role in our daily life, decorates our living environment, and brings us a positive visual and psychological feeling. The feeling of color is the most popular form of general aesthetics (Marx \& Engels, 1998), and people's sensitivity to color far exceeds their sensitivity to shape, because from the perspective of visual physiology, in the initial stage, the human eye first what is captured in the color element, so color is one of the important ways for human beings to understand and express the world (Song, 2006). In addition, human cognition and application of color directly reflect the world 
outlook and values of an ethnic group, and it is also a sign of the difference between cultural regions. At present, with the continuous advancement of economic development and modernization process, cities are affected by modernism, internationalism and other design trends. The visual color representation of the city shows a certain degree of convergence, while the national cultural characteristics are gradually fading. Although urban color is currently exploring an application method that combines modern visual expressions with local regional cultural colors, the simple application of color that lacks in-depth understanding of historical context and color context is lost to the east, making the city's visual color environment deterioration. Therefore, it is necessary to explore a theoretically based urban color application method. This article attempts to carry out a mutually corroborating research from two perspectives of urban historical color and contemporary urban color. Specifically, the first is to use the literature research method to verify the color history and culture of the city, to clarify the sources and functions of various colors in the history, and to summarize the unique colors in the regional culture; the second is to use the field research method to investigate the color history and culture of the city. The color representations displayed in the current urban development are collected, analyzed and summarized, and analyzed and compared with the historical colors, exploring the color connection and law between the two, and providing a certain degree for the future development and application of urban colors in accordance with.

\section{Textual Research on the Color of the City's History}

Color, as an objectively existing physical phenomenon and element of visual perception, does not have specific emotional and symbolic meanings. Urban colors are given a specific cultural background, resulting in complex color psychology and color cultural phenomena in the region. Urban color through the accumulation of history will have a unique culture that reflects the way of thinking and cognitive style of local residents, related to the value of the color judgment. The well-known structuralist pointed out that when we organize and write history, we will imitate our understanding of nature, so we divide and arrange cultural products and look for them in the deep structure of the material layer (Leach, 1967). Therefore, the textual research on the historical color of the city will start from the three aspects of China's unique "ritual", "use", and "emotion", representing the three levels of consciousness of thinking, the function of things, and human emotion. Take Chengdu, one of the top ten ancient capitals, as an example for analysis and elaboration.

\subsection{Color Is in Etiquette-Unique Etiquette Color View}

With the deepening of people's understanding and the expansion of creation practice, the choice of colors has also changed from spontaneous to conscious, but the powerful ritual restrictions under the unique cultural environment keep the colors of Chinese creation far away from the realm of complete freedom. 
People's use of color is deeply affected by the ritual color concept, which limits the full expression of the color emotion of the main body of creation. The use of colors in accordance with rituals is a typical feature of traditional Chinese color applications. The dynasties of the past have formulated strict standards for color application. The color selection and use of folk crafts at the grassroots level is obviously restricted by this ritual color concept. The organization of traditional Chinese society is precisely the integration of Confucian ideology and social political organization represented by "li", that is, traditional Chinese society relies on "li" to maintain order and rationality and show ideology. Under this order, colors are closely linked with "rituals", composed of five positive colors of blue, red, white, black, and yellow, as well as the colors of the sum of tones, which are expressed in "the color of clothes, the color of clothes". "Han is the soil, Germany and Huang" and other concepts.

In short, the traditional patriarchal system of the integration of family and country determines our nation's tradition of attaching great importance to ethical norms and moral education, and the application of creative colors is also deeply affected by it. The colors of many folk creations are also subordinate to the political purpose of the ruling class to administer the country and maintain moral integrity. As a result, color has the social value function of distinguishing honor and inferiority and distinguishing honor and inferiority. Obviously, this kind of ritual color concept restricts the naturalness and freedom of the people's creation of color, and affects the innovation of traditional creation of color practice.

According to the historian, from the Warring States period, there were 9 regimes that regarded Chengdu as their capital (Shi, 1991). If you count the Sanxingdui and Jinsha sites, then there are 11 regimes that established the capital in Chengdu in history. According to the above, it can be seen that Chengdu's colors are of class diversity, ranging from royal power to the common people, which can be reflected in the historical colors of Chengdu. Color samples from Chengdu cultural relics were used for color extraction. Among them, the unique ancient Shu civilization and Jinsha culture in Chengdu area, with its iconic "golden yellow" and "bronze green" color symbols, carry on long-term cultural inheritance in public spaces and public facilities and are recognized by the public. For example, the color matching of green and gold on the lampposts of Tianfu Square, the yellow-green color matching of Chengdu taxis, and the golden sun bird logo in Chengdu subway vehicles and subway stations. The "yellow tone" extracted from the city's ancient buildings and cultural relics not only represents the splendid culture of Chengdu, but also contains the respect for rituals in Chengdu's history. Therefore, the yellow color can be used as the historical color of Chengdu for sample extraction and analysis.

\subsection{Color Is for Use-The Aesthetic Color View of Using Beauty as a Whole}

Colors appear simple and pragmatic in folk creations, and serve the real life of 
people. The use of craftsmanship focuses on the level of actual needs in life, full of secular interest and distinctive life characteristics. The formation of the earliest color concepts is often connected with human existence, and then is given symbolic and even cultural significance (Tu, 1993). The practical color concept is applied to all aspects of people's lives, and the concept of focusing on practicality has become a folk the foundation of color application practice, a prominent manifestation is the memorable and narrative function of color. Color is used to indicate ethnicity, gender, age, marriage or not, social role and other information. It has existed since the period of clan society, and color has become ethnic group. Symbols for identification, together with patterns, materials and other formal languages, convey the values and social consciousness that the ethnic group complies with, and use this to stimulate group identity. In addition, the use of color not only includes the most direct physical and practical meaning of color, but also includes the aesthetics of color represented by spirituality. Tu Guohong (1993) argues that in folk art, color is a kind of metaphor and psychological suggestion. It uses a specific image of color and form to satisfy the mentality of good fortune, blessings and prosperity, and prosperity and peace. It shows the people's vision and the pursuit of happiness in life. The inner desire to seek good fortune and avoid evil, this way of color selection and cognitive attitude is based on the specific cultural background of our nation, reflects the distinctive national cultural characteristics, has multiple cultural meanings and rich cultural connotations.

Another practical condition is the convenience of color selection. As a famous historical and cultural city with the urban style of Western Sichuan, Chengdu's urban color should be derived from Chengdu's peculiar pragmatism. From a geographical point of view, Chengdu is located in the western part of the Sichuan Basin. It has climate characteristics such as the same period of rain and heat, high humidity, short sunshine time, and weak atmospheric diffusion. Therefore, due to the influence of the natural environment, the exterior walls of traditional Western Sichuan houses are painted with white ash. It not only prevents moisture but also increases the refractive index of sunlight to supplement lighting; the roof is mixed with straw in the blue tiles, which can solve the roof drainage problem and play a certain role in heat insulation. The building materials for the residential buildings in West Sichuan are made from local materials, mainly wood, stone, straw, and blue tiles. The materials themselves are characterized by low purity and simple and elegant color style. It is precisely because of the specific natural environment that gave birth to the unique urban appearance of western Sichuan, which defines the simple and implicit "composite gray" color attribute of Chengdu.

\subsection{Color Is in Emotion-The Influence of Color under National Emotion}

The selection of colors is human-centered, and through human processing, selection and creation in advance, human consciousness, emotions and concepts 
will inevitably be integrated into the color, giving the color a distinctive human imprint. The beauty of color, the beauty is pleasing to the eye, and even more pleasant. Emotions are often the subjective psychological reflections of people to the extent to which reality meets their specific needs. Emotions are born because of advantages and disadvantages. As far as the colors of creation are concerned, only colors that suit their purpose can be recognized and accepted. The utilitarian purpose of the people is to revolve around the production and life of survival, seeking profit, and avoiding harm. The value of color often lies in the emotional stimulation and the satisfaction of the ideas that it brings. People often understand and use color according to their own personal interests and utilitarian wishes (Zheng, 2021). In short, the color concept of folk creation is secular and utilitarian. It is based on material enjoyment and aesthetic entertainment. It focuses on the visual beauty of color itself, but it is not pure aesthetics. It is associated with a broader social meaning than visual aesthetics. One can glimpse the people's national mentality and spiritual pursuit, Chinese folk cultural concepts are formed under the realistic conditions of scarcity, and a subjective consciousness system with the central intention of surpassing the real dilemma and getting rid of the suffering of life (Feng, Chen, \& Li, 2007). In the structure of folk cultural concepts the concept of need expressed in psychological forms such as willingness, hope, ideals, etc. is always in an active position. It promotes and regulates subject consciousness activities and adheres to a purposeful dimension. The people use color to create an ideal world, and people hope obtain a great sense of psychological satisfaction from it, soothe life with color, and realize the compensation for the difficult reality. The colors of creation show people's aspirations for life and embody the spirit of the nation.

China has always divided people and cultural traditions by "south and north". Chengdu people in southwestern China have both the agility of the south and the optimism cast by survival in a harsh environment. In ancient times, Sima Xiangru and the poet Du Fu recited poems against each other. Today, Chengdu people look at each other in tea houses. The leisurely sentiment of Chengdu people is even more reflected in the use of "leisure green". For example, this kind of green can be seen everywhere on the mahjong tiles, one of the must-have entertainment methods for Chengdu people. In addition, due to the humid climate characteristics of Chengdu, Chengdu people have widely accepted peppers and penetrated into all aspects of Chengdu people's lives, thus forming the straightforward and strong character of Chengdu people, and at the same time forming the color of Chengdu people towards "chili red". For example, in some traditional New Year pictures, a large area of red is often used as the main visual color to avoid evil in the town house.

\subsection{Summary}

Through the textual research on the three dimensions of ritual, service and sentiment in Chengdu's historical color, the evolution and law of the application of Chengdu's historical color can be summarized, as shown in Figure 1. 


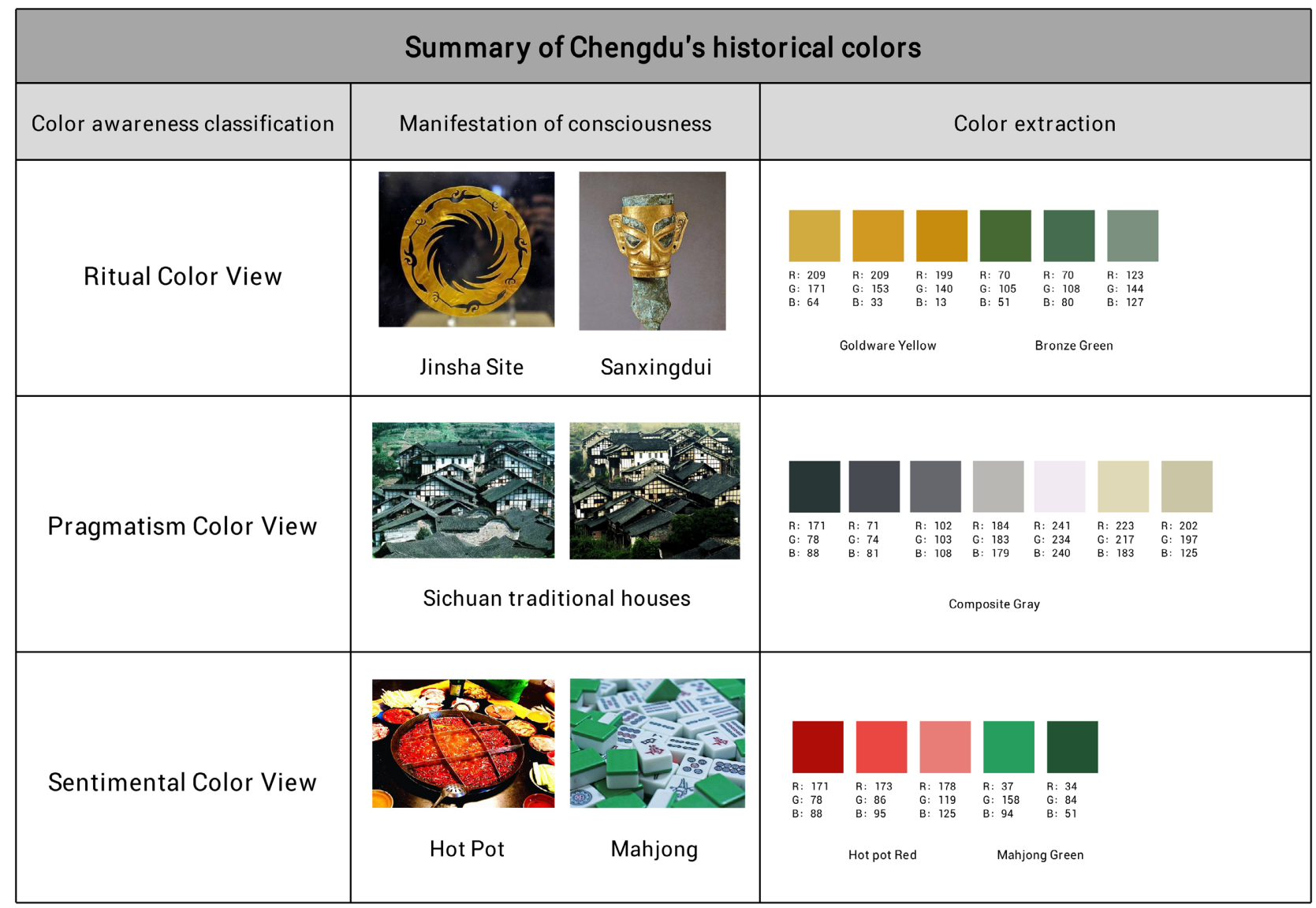

Figure 1. Chengdu historical color summary table. Source: author self-made.

\section{Extraction of Contemporary Urban Colors}

Before you begin to format your paper, first write and save the content as a separate text file. Keep your text and graphic files separate until after the text has been formatted and styled. Do not use hard tabs, and limit use of hard returns to only one return at the end of a paragraph. Do not add any kind of pagination anywhere in the paper. Do not number text heads-the template will do that for you.

Finally, complete content and organizational editing before formatting. Please take note of the following items when proofreading spelling and grammar.

\subsection{Method}

There are many ways to describe color quantitatively. Qualitatively, there are mainly the HV/C model of the Munsell color system, the RGB model of the ternary color ratio, and the HSB (body color, color difference, brightness) model with the human eye as the detector (Cheng \& Tan, 2018). The CMYK model is based on the ink mixing ratio; the CIECOLOR system is described by a pure mathematical model and so on. In this survey, the RGB model is selected to describe the color.

The most notable features of current color science research are: 1) the choice 
of quantitative experimental methods; 2) the transformation of color perception media from human eyes to digital devices; 3 ) the transformation of color expression from perceptual definition to quantitative data analysis. Therefore, we use a quantitative analysis method to summarize the frequency of color appearance and extract the color interval with the highest frequency.

The specific steps of this survey are: 1) extract visual colors in representative locations in Chengdu, mainly by taking color images; 2) pixelate the collected images to improve the efficiency of color extraction; 3) obtain the main color interval by analyzing the color appearance frequency in each color image; 4) compare and analyze the historical colors, and find the associated colors as the result, as the city color.

\subsection{Descriptive Analysis of Data Sources and Variables}

\subsubsection{Data Sources}

The most intuitive way to extract city colors comes from the style and features of the main urban area (Jing \& Huo, 2011). In order to build a distinctive national central city and enhance the image of Chengdu, the Chengdu Urban Planning Bureau issued the Optimization Plan for Chengdu Medium Excellent Planning. It was proposed to form a "Medium Excellent" plan with the Fifth Ring Road as the boundary Scope, reshape the main urban area (Zhao et al., 2009). Therefore, the collection of samples is mainly concentrated in the main urban areas where historical relics and contemporary planning and design are combined, mainly in five locations such as Taikoo Li, Wenshu Monastery, Kuanzhai Alley, Wuhou Temple, and Sichuan University, Chunxi Road, Yulin famous streets such as $\mathrm{Lu}$ and Jinjiang Road are supplemented by color sample collection. The specific collection method is as follows: the collection is divided into 7 groups, using the same photography equipment, to take photos of the visual color representations of the above locations between $10 \mathrm{am}$ and $12 \mathrm{am}$ on the same day, and the number of collections at each location is 100 . Ensure that the timeliness of the collection of samples is the same, and the diversity of the samples.

\subsubsection{Variable Description}

In the process of color data extraction, there are many variables that affect the accuracy of color data. By scientifically analyzing and describing these variable factors, and proposing and searching for scientific control methods, our data is as scientific and accurate as possible. As shown in Figure 2.

\subsection{Color Extraction Process}

After variable analysis and control, the color extraction method is determined. Specifically, the extraction process is divided into 4 steps. The first step is to collect the color image of the target object; the second step is to perform a unified pixelization process on the collected color image, which is more convenient for color extraction; the third step is to the colors in the color image are extracted separately, which are divided into effective colors and invalid colors; the fourth 
step is to extract colors, and determine the RGB value and color interval of the color. As shown in Figure 3 below.

\begin{tabular}{|l|l|l|l|}
\hline $\begin{array}{l}\text { Influence factor } \\
\text { classification }\end{array}$ & Influence factor & Mode of action & variable control \\
\hline Physical impact & Illumination & $\begin{array}{l}\text { With the change of sunlight, the color } \\
\text { effect presents the law of change in } \\
\text { the morning, at noon and in the } \\
\text { afternoon }\end{array}$ & $\begin{array}{l}\text { Samples were collected from } 10 \\
\text { am to } 12 \text { am on the same day }\end{array}$ \\
\hline Physical impact & Object place & $\begin{array}{l}\text { Different directions of objects lead to } \\
\text { different degrees of light }\end{array}$ & $\begin{array}{l}\text { The object selectively extracts } \\
\text { the better color in the image }\end{array}$ \\
\hline Physical impact & Object structure & $\begin{array}{l}\text { During the long time, object aging } \\
\text { and degeneration }\end{array}$ & $\begin{array}{l}\text { The objects decay } \\
\text { Uncontrollable }\end{array}$ \\
\hline Physical impact & Observation & $\begin{array}{l}\text { Different observation equipment } \\
\text { makes color extraction unnecessary }\end{array}$ & $\begin{array}{l}\text { Use the same observation } \\
\text { equipment }\end{array}$ \\
\hline Visual impact & Viewing angles & $\begin{array}{l}\text { The color of the object is different } \\
\text { with different perspective }\end{array}$ & $\begin{array}{l}\text { Extract the color of the object } \\
\text { from as many angles as possible }\end{array}$ \\
\hline Visual impact & Collection team & $\begin{array}{l}\text { The data collected by different groups } \\
\text { are uneven }\end{array}$ & \begin{tabular}{l} 
Large amount of data collection \\
\hline
\end{tabular} \\
\hline
\end{tabular}

Figure 2. The analysis table of influence factors of color. Source: author self-made.

\section{Brief demonstration of color extraction steps}

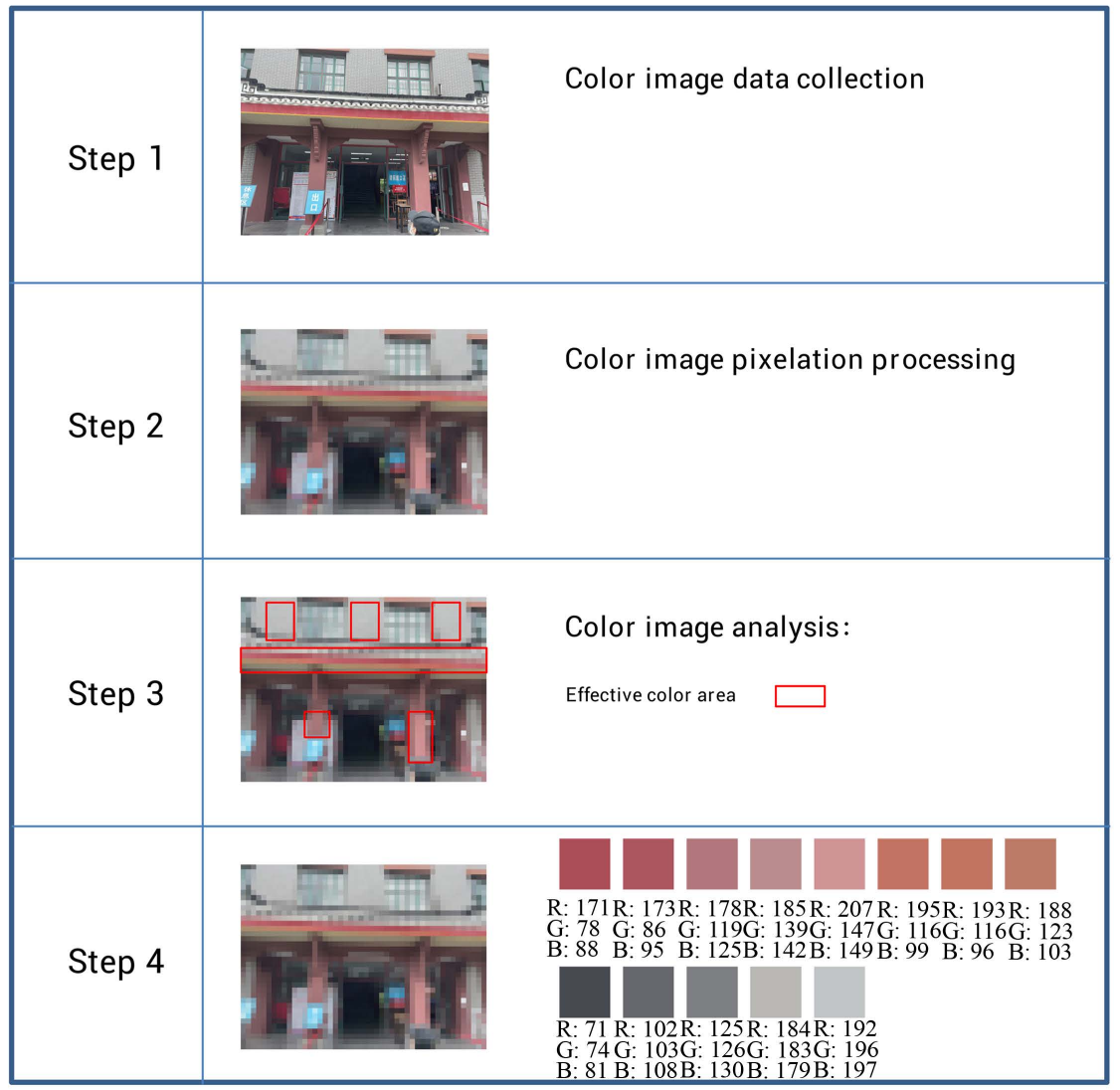

Figure 3. The table of brief demonstration of color extraction steps. Source: author self-made. 
In the color collection process of the target object, each presentation surface selects three different perspectives for color collection, namely the front view, the left side and the right side, and collects the color presentation from different angles as much as possible to improve the color collection process accuracy. As shown in Figure 4.

When analyzing and extracting the collected color images, the colors in the image are divided into effective colors and ineffective colors. The effective colors are better light-receiving, which can fully reflect their own color tendency; the ineffective colors are mostly the backlight and dark parts. The color tendency is not obvious. As shown in Figure 5.

\subsection{Color Extraction Analysis and Results}

We analyzed the color images of these five representative locations in Chengdu, and extracted a large number of visual colors. Through the comparison and analysis of the color repetition rate and similarity rate, we summarized the representative colors of each location, such as Figure 6 shows; further analysis, we find that Chengdu contemporary color presentation is mainly concentrated in these four colors, namely yellow, red, green, gray, and coincides with the historical color summarized above, which proves the urban color at the same time, we further determined the RGB value range of these 4 colors as the visual color of the city.

Figure 7 below for a specific range of color values.

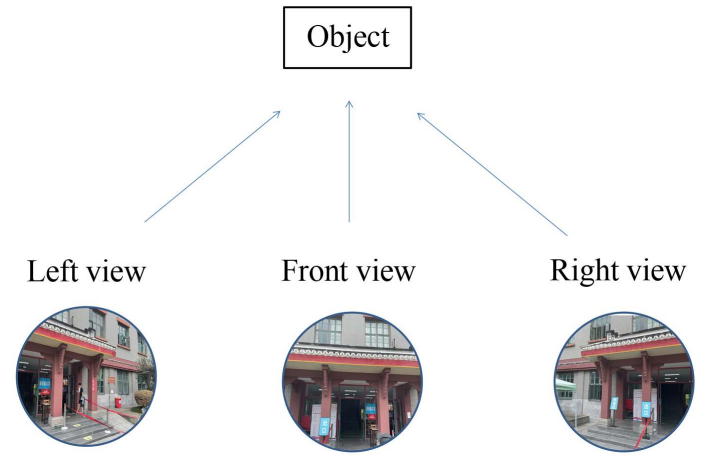

Figure 4. Object acquisition angle schematic. Source: author self-made.

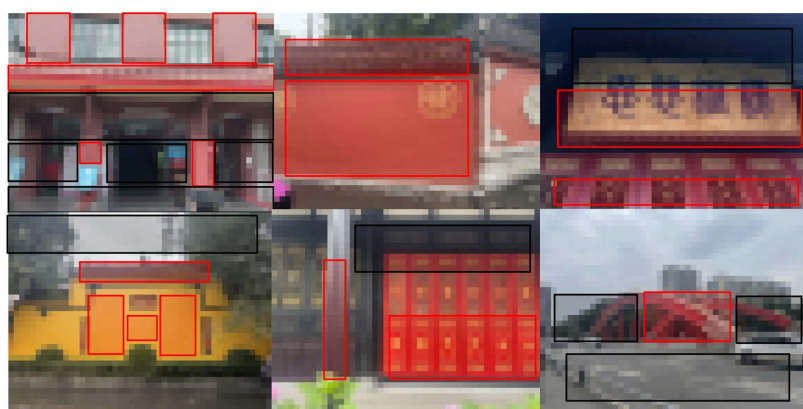

Effective color area: Invalid color area:

Figure 5. Image color extraction and analysis. Source: author self-made. 


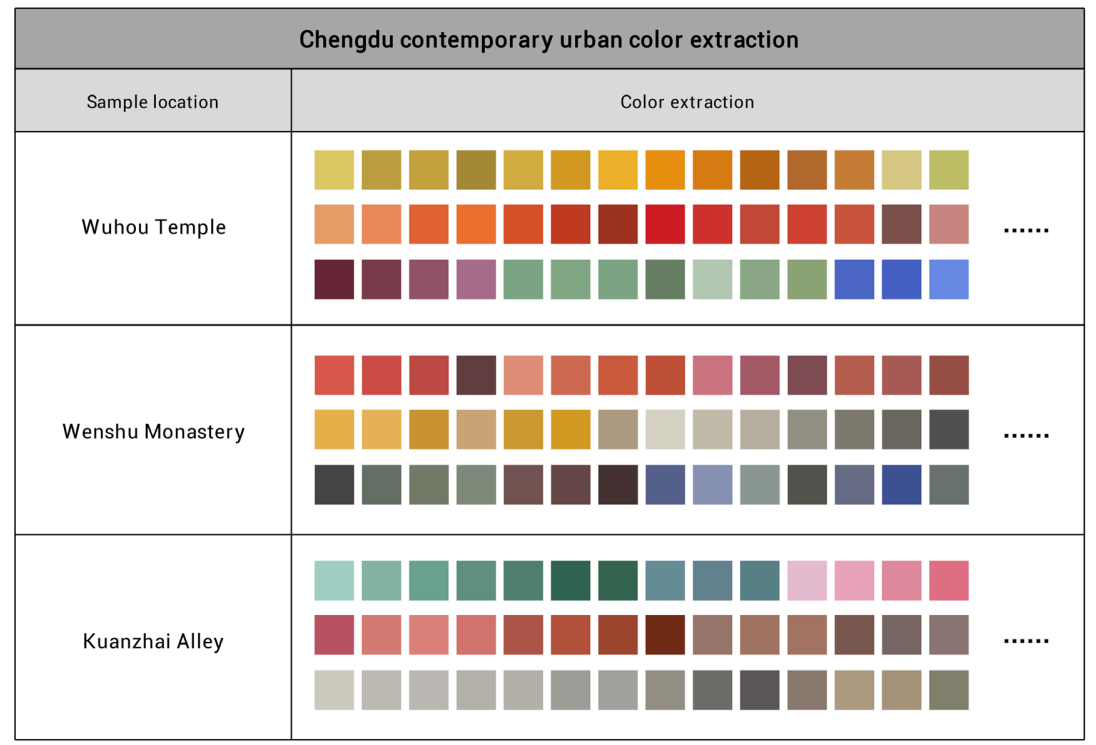

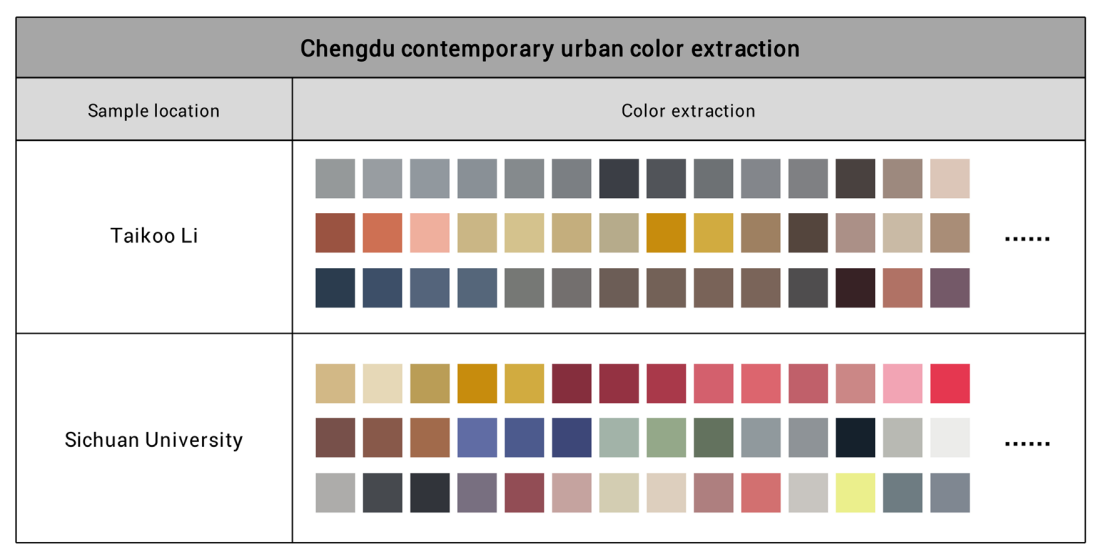

Figure 6. Color extraction overview map. Source: author self-made.

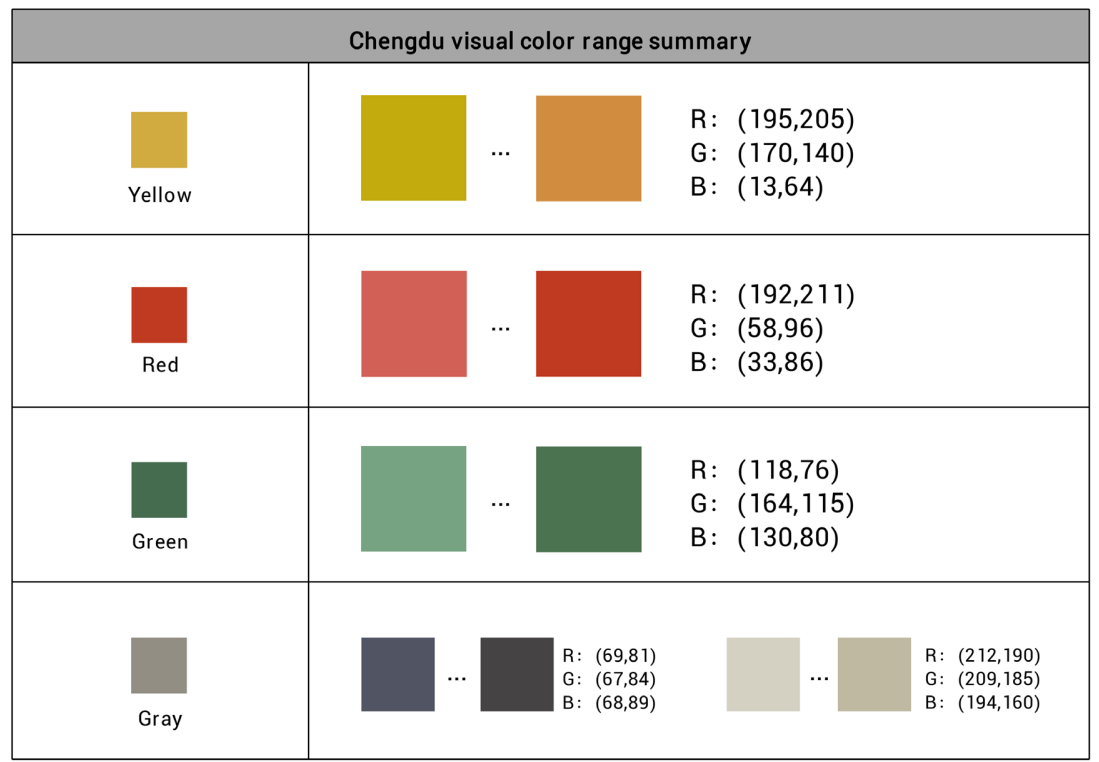

Figure 7. City color specific numerical interval map. Source: author self-made. 


\section{Conclusion}

Although urban visual color research has strong objective cognition and practical application evaluation functions in the process of urbanization, the in-depth study of urban color planning and design still requires a combination of historical and current analysis of urban color. This research shows the process of textual research on historical colors and research on the application of current colors. The value of urban visual color research lies in the use of color theory to analyze the past and present state of color elements and their interaction from the perspective of visual aesthetics, so as to summarize the coloring law of the analyzed object. This research belongs to the field of vision science. Nevertheless, the new ideas and new methods brought about by interdisciplinary research are what we expect. Traditional color research has been very developed and has achieved rich results, but in different fields, the choice of color research methods, the color space used, and other color research methods are not always the same. The ideology behind the specific objects attached to the color composition determines the law of color change and the final manifestation, and at the same time reflects the city's regional culture, ideas, folklore, etc. The color is only one of these ideological representations. In addition, the research and exploration of this paper can provide the following suggestions for the application of urban visual color: 1) from the perspective of the unique color cultural inheritance of the city and the region, respect the application of color in the cultural tradition, understand some norms and taboos of the use of color, and adjust the color planning of some areas in the city to local conditions. For example, the color use of visual signs near Wuhou Temple in Chengdu. It should be considered comprehensively according to the law and tradition of color application inherited from Wuhou Temple; 2) from the perspective of economic practicality, through the calculation of cost and consumption, consider the use proportion of urban color and the maintenance of color continuity, and choose the color collocation with appropriate cost and high continuity; 3) establish a feedback database of urban color residents, timely investigate and analyze the visual color preference of contemporary urban residents, and select color applications with high recognition of residents to improve the comfort of urban living environment. Therefore, in the specific urban color design practice, we should pay more attention to the harmony between the color and the culture behind it. Urban visual color research has great application potential in planning and design. Although this subject has not received widespread attention, it has been highly praised by many Chinese scholars. Taking this article as an example, through a lot of design practice research, we have a clearer understanding of the applicability of historical colors in contemporary times, as well as specific methods and limitations of operation. For example, the cultural experience and emotional changes influenced by urban colors, the quantitative and qualitative analysis of color culture and emotions can be seen as a guide for the further development of the discipline. This research aims to put the application of urban visual color in specific 
urban color design practice, and provide evidence-based color theory support. Therefore, as a supplement to the method of urban color design, the study of urban visual color deserves wider attention and further development.

\section{Conflicts of Interest}

The authors declare no conflicts of interest regarding the publication of this paper.

\section{References}

Cheng, Y., \& Tan, M. (2018). The Quantitative Research of Landscape Color: A Study of Ming Dynasty City Wall in Nanjing. Color Research \& Application, 43, 436-448. https://doi.org/10.1002/col.22203

Elliot, A. J., \& Maier, M. A. (2007). Color and Psychological Functioning. Current Directions in Psychological Science, 16, 250-254. https://doi.org/10.1111/j.1467-8721.2007.00514.x

Feng, D., Chen, L. Y., \& Li, D. (2007). The Expressive Function and Cultural Significance of Color in Folk Art. Journal of Zhengzhou University (Philosophy and Social Sciences), 162-165.

Jing, X. P., \& Huo, X. P. (2011). Study on Urban Color Control in Xi'an Old City. Urban Issues, 2, 36-39.

Leach, E. (1967). The Structural Study of Myh and Totemism. Routledge, 4, 78-79.

Shi, L. H. (1991). An Overview of Ancient Chinese Capitals (6). Shaanxi Normal University News, 2, 66-73.

Marx, K., \& Engels, F. (1998). Marx \& Engels Collected Works Vol 37: Karl Marx Capital: Volume 3. London: Lawrence \& Wishart.

Song, J. M. (2006). Thoughts on "National Color". The Art of Observation, 1, 5-9.

Tu, G. H. (1993). Chinese Primitive Art Spirit. China Publishing Yearbook, 8, 451.

Wang, J., Zhang, L., \& Gou, A. (2020). Study on the Preference of City Color Image Selection Based on the Logistic Model: A Case Study of Shanghai. Color Research \& Application, 45, 542-557. https://doi.org/10.1002/col.22487

Zheng, Y. F. (2021). On Chinese Folk Art. Fine Arts Education Research, 9, 70-71.

Zhao, C. S., Wu, J. Z., Wu, C., et al. (2009). Urban Color Planning: A Case Study of Tianjin Urban Color Planning. Urban Plan, 33, 36-40. 